\title{
Transcriptomic dissection of tongue squamous cell carcinoma
}

\author{
Hui Ye ${ }^{\dagger 1}$, Tianwei $\mathrm{Yu}^{\dagger 2}$, Stephane Temam ${ }^{3,4}$, Barry L Ziober5, \\ Jianguang Wang ${ }^{6}$, Joel L Schwartz ${ }^{7,8}$, Li Mao ${ }^{3}$, David T Wong ${ }^{9}$ and \\ Xiaofeng Zhou*1,8,10
}

\begin{abstract}
Address: ${ }^{1}$ Center for Molecular Biology of Oral Diseases, College of Dentistry, University of Illinois at Chicago, Chicago, IL, USA, ${ }^{2}$ Department of Biostatistics, Rollins School of Public Health, Emory University, Atlanta, GA, USA, ${ }^{3}$ Department of Thoracic/Head and Neck Medical Oncology, University of Texas, MD Anderson Cancer Center, Houston, TX, USA, ${ }^{4}$ Department of Head and Neck Surgery, Institut Gustave-Roussy, Villejuif, France, ${ }^{5}$ Department of Otorhinolaryngology - Head and Neck Surgery, University of Pennsylvania Health System, Philadelphia, PA, USA, ${ }^{6}$ Department of Oral \& Maxillofacial Surgery, the Second Affiliated Hospital of Sun Yat-sen University, Guangzhou, China, ${ }^{7}$ Oral Medicine \& Diagnostic Sciences, College of Dentistry, University of Illinois at Chicago, Chicago, IL, USA, ${ }^{8}$ Graduate College, UIC Cancer Center, University of Illinois at Chicago, Chicago, IL, USA, ${ }^{9}$ Dental Research Institute, School of Dentistry, Jonsson Comprehensive Cancer Center, University of California at Los Angeles, Los Angeles, CA, USA and ${ }^{10}$ Guanghua School \& Research Institute of Stomatology, Sun Yat-sen University, Guangzhou, China

Email: Hui Ye - huiye@uic.edu; Tianwei Yu - tyu8@sph.emory.edu; Stephane Temam - lmao@mdanderson.org;

Barry L Ziober - bziober@mail.med.upenn.edu; Jianguang Wang - wjgmin@hotmail.com; Joel L Schwartz - joschwar@uic.edu; Li Mao - lmao@mdanderson.org; David TWong - dtww@ucla.edu; Xiaofeng Zhou* - xfzhou@uic.edu

* Corresponding author †Equal contributors
\end{abstract}

Published: 6 February 2008

BMC Genomics 2008, 9:69 doi:10.1186/147/-2164-9-69

This article is available from: http://www.biomedcentral.com/I47|-2/64/9/69

(C) 2008 Ye et al; licensee BioMed Central Ltd.

This is an Open Access article distributed under the terms of the Creative Commons Attribution License (http://creativecommons.org/licenses/by/2.0), which permits unrestricted use, distribution, and reproduction in any medium, provided the original work is properly cited.

Received: 15 August 2007

Accepted: 6 February 2008

\begin{abstract}
Background: The head and neck/oral squamous cell carcinoma (HNOSCC) is a diverse group of cancers, which develop from many different anatomic sites and are associated with different risk factors and genetic characteristics. The oral tongue squamous cell carcinoma (OTSCC) is one of the most common types of HNOSCC. It is significantly more aggressive than other forms of HNOSCC, in terms of local invasion and spread. In this study, we aim to identify specific transcriptomic signatures that associated with OTSCC.

Results: Genome-wide transcriptomic profiles were obtained for 53 primary OTSCCs and 22 matching normal tissues. Genes that exhibit statistically significant differences in expression between OTSCCs and normal were identified. These include up-regulated genes (MMPI, MMPI0, MMP3, MMPI2, PTHLH, INHBA, LAMC2, IL8, KRTI7, COLIA2, IFI6, ISGI5, PLAU, GREMI, MMP9, IFI44, CXCLI), and downregulated genes (KRT4, MAL, CRNN, SCEL, CRISP3, SPINK5, CLCA4, ADHIB, PII, TGM3, RHCG, PPPIR3C, CEACAM7, HPGD, CFD, ABCA8, CLU, CYP3A5). The expressional difference of IL8 and MMP9 were further validated by real-time quantitative RT-PCR and immunohistochemistry. The Gene Ontology analysis suggested a number of altered biological processes in OTSCCs, including enhancements in phosphate transport, collagen catabolism, I-kappaB kinase/NF-kappaB signaling cascade, extracellular matrix organization and biogenesis, chemotaxis, as well as suppressions of superoxide release, hydrogen peroxide metabolism, cellular response to hydrogen peroxide, keratinization, and keratinocyte differentiation in OTSCCs.
\end{abstract}

Conclusion: In summary, our study provided a transcriptomic signature for OTSCC that may lead to a diagnosis or screen tool and provide the foundation for further functional validation of these specific candidate genes for OTSCC. 


\section{Background}

Head and neck/oral squamous cell carcinoma (HNOSCC) is a complex disease arising in various organs, including oral cavity, tongue, pharynx, and larynx. Tumors from these different sites have distinct clinical presentations and clinical outcomes, and are associated with different risk factors [1] and genetic characteristics [2]. In this study, we focused on the oral tongue squamous cell carcinomas (OTSCC), one of the most common sites for HNOSCCs. The incidence of OTSCC is actually increasing in young and middle age groups [3-5]. OTSCC is significantly more aggressive than other forms of HNOSCCs, with a propensity for rapid local invasion and spread [6].

Cancer cells harbor genetic alterations which are translated into unique expression patterns. These patterns may segregate cancer cells from normal tissue of the same origin and serve as a molecular biomarker. Moreover, expression pattern changes may occur far earlier than clinical disease detection. The identification of such patterns has significant translational values for early detection and diagnosis, as well as for identifying novel therapeutic targets. While several recent studies have attempted to identify expression patterns for HNOSCCs [7-10], to our knowledge, no study has been devoted to identify the unique expression pattern for OTSCC. In this study, we aim to identify the specific transcriptomic/expression patterns that associated with OTSCC.

\section{Results and discussion}

Genome-wide gene expression profiles were obtained on 53 OTSCC samples and 22 normal matching samples. Principal Component Analysis (PCA) was performed based on all the probesets utilized in our microarray analysis. Apparent separation between OTSCC and normal groups was observed with a few outliers (Figure 1). Genes showing statistically significant differences in expression level were identified using RMA and a mixed-effects model as described in the Materials and Methods section. A signature gene set that consists of 35 genes was created using stringent statistical criteria (fold change $>4$, and FDR values $<0.0001$ ) (Table 1 ). Comprehensive lists of genes showing statistically significant upregulations (fold change $>2$, and FDR values $<0.01$ ) or downregulations in expression in OTSCC were presented in Supplement Table S1 [see additional file 1] and S2 [see additional file 2], respectively.

In this study, we identified and validated several interesting potential biomarkers for OTSCC diagnosis. One interesting observation is that 5 members of the Matrix Metalloproteinase (MMP) family (MMP1 MMP3, MMP9, MMP10, and MMP12) are among the genes that most significantly upregulated, which may contribute to the aggressive nature of the OTSCC. MMPs are a large family

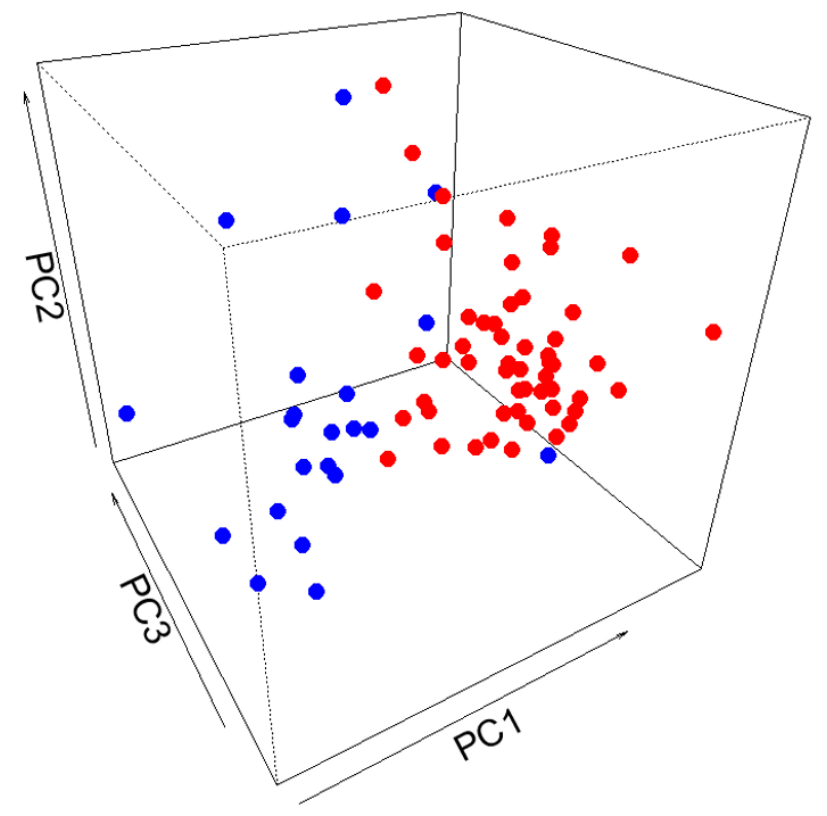

Figure I

Principle component analysis. Global gene expression profiles on 53 OTSCC and 22 matching normal samples were obtained as described in Materials and Methods section. Principle Component (PC) analysis was performed based on the expression profiles of samples. The first 3 PCs were plotted. Red: OTSCC, Blue: normal.

of proteinases which remodel extracellular matrix (ECM) components and play a significant role in tumor development, survival, invasion and metastasis [11-13]. Several members of the MMP family have been considered to be important biomarkers for diagnosis and prognosis as well as potential therapeutic targets for many types of cancers, including HNOSCC [14]. Our recent study suggested that up regulation of the MMP9 gene is associated with advanced OTSCC and has predictive value for the identification of lymph node metastasis [15]. Here, our data further suggested that MMP9 is one of the biomarkers for the detection of OTSCC. We also observed 2 chemokines (IL8 and CXCL1) to be among the most significantly upregulated genes in OTSCC. The increase in the protein and mRNA of IL8 gene has been suggested as a biomarker for the early detection of oral cancer $[16,17]$. Our data provided independent validation for this biomarker at the disease tissue level, and suggested that the increase of IL8 molecules (mRNA and protein) is due at least in part to the increased expression of gene in the disease tissues. CXCL1, also known as growth-regulated oncogene 1 (Gro-1), is vital for the survival, progression and invasion of several cancer types $[18,19]$, including oral cancer [20]. Our results here further confirmed the importance of CXCL1 in the tumorgenesis of tongue cancer. Other inter- 
Table I: Signature gene sets for OTSCC

\begin{tabular}{|c|c|c|c|}
\hline Symbol & Probe ID & Gene Name & Location \\
\hline \multicolumn{4}{|c|}{ Upregulated genes in OTSCC } \\
\hline MMPI & 204475_at & matrix metalloproteinase I & I I q22.3 \\
\hline MMPIO & 205680_at & matrix metalloproteinase 10 & I lq22.3 \\
\hline MMP3 & 205828_at & matrix metalloproteinase 3 & I Iq22.3 \\
\hline MMPI2 & 204580_at & matrix metallopeptidase 12 & I lq22.3 \\
\hline PTHLH & 211756_at & parathyroid hormone-like hormone & $12 p|2.1-p| 1.2$ \\
\hline INHBA & 210511_s_at & inhibin, beta $A$ & $7 p 15-p 13$ \\
\hline LAMC2 & 202267_at & laminin, gamma 2 & $|q 25-q 3|$ \\
\hline IL8 & 202859_x_at & interleukin 8 & $4 q \mid 3-q 21$ \\
\hline KRTI7 & 205157_s_at & keratin 17 & $|7 q| 2-q 2 \mid$ \\
\hline COLIA2 & 202404_s_at & collagen, type I, alpha 2 & $7 q 22.1$ \\
\hline $\mathrm{IFI} 6$ & 204415_at & interferon, alpha-inducible protein 6 & $1 \mathrm{p} 35$ \\
\hline ISGI5 & 205483_s_at & ISG I5 ubiquitin-like modifier & Ip36.33 \\
\hline PLAU & 205479_s_at & plasminogen activator, urokinase & $10 q 24$ \\
\hline GREMI & 218468_s_at & gremlin I & $15 q \mid 3-q 15$ \\
\hline MMP9 & 203936_s_at & matrix metallopeptidase 9 & $20 q|1.2-q| 3.1$ \\
\hline IFI44 & 214453_s_at & interferon-induced protein 44 & $|p 3| . \mid$ \\
\hline CXCLI & 204470_at & chemokine (C-X-C motif) ligand I & $4 q 21$ \\
\hline \multicolumn{4}{|c|}{ Downregulated genes in OTSCC } \\
\hline KRT4 & 213240_s_at & keratin 4 & $12 q|2-q| 3$ \\
\hline MAL & 204777_s_at & mal, T-cell differentiation protein & $2 c e n-q 13$ \\
\hline CRNN & 220090_at & Cornulin & $|q 2|$ \\
\hline SCEL & 206884_s_at & Sciellin & $13 q 22$ \\
\hline CRISP3 & 207802_at & cysteine-rich secretory protein 3 & $6 p / 2.3$ \\
\hline SPINK5 & 205185_at & serine protease inhibitor, Kazal type 5 & $5 q 32$ \\
\hline CLCA4 & 220026_at & chloride channel, calcium activated, family member 4 & $|p 3|-p 22$ \\
\hline ADHIB & 2096|2_s_at 209613_s_at & alcohol dehydrogenase IB (class I), beta polypeptide & $4 q 21-q 23$ \\
\hline PII & 206605_at & 26 serine protease & $12 q 13.1$ \\
\hline TGM3 & 206004_at & transglutaminase 3 & $20 q 11.2$ \\
\hline RHCG & 219554_at & Rhesus blood group, $\mathrm{C}$ glycoprotein & $15 q 25$ \\
\hline PPPIR3C & 204284_at & protein phosphatase I, regulatory (inhibitor) subunit $3 \mathrm{C}$ & $10 q 23-q 24$ \\
\hline CEACAM7 & 206199_at & carcinoembryonic antigen-related cell adhesion molecule 7 & $19 q 13.2$ \\
\hline HPGD & 203914_x_at & hydroxyprostaglandin dehydrogenase I5-(NAD) & $4 q 34-q 35$ \\
\hline CFD & 205382_s_at & D component of complement (adipsin) & $19 p 13.3$ \\
\hline $\mathrm{ABCA} 8$ & 204719_at & ATP-binding cassette, sub-family $A(A B C I)$, member 8 & $17 q 24$ \\
\hline CLU & 222043_at & Clusterin & $8 p 21-p 12$ \\
\hline CYP3A5 & 214235_at & cytochrome P450, family 3 , subfamily A, polypeptide 5 & $7 q 21.1$ \\
\hline
\end{tabular}

* The complete lists of upregulated and downregulated transcripts in OTSCCs were presented in Supplement Table SI and S2, respectively.

esting observations include the up-regulation of KRT17 (associated with invasion and proliferation) and downregulation of KRT4 (which is associated with squamous cell differentiation), suggesting the potentially distinct roles of KRT genes in tongue SCC development and progression. In addition to those identified biomarkers, our results will also serve as a valuable reference data set for future development and validation of biomarkers for detection, diagnosis and prognosis of tongue cancer.

To test the utility of this 35-gene signature gene set for classifying OTSCC and normal groups, average linkage hierarchical clustering analysis was performed. As illustrated in Figure 2, our results demonstrated that this 35gene set provides classification power for OTSCC based on gene expression analyses, which misclassified two cases for each of two groups (a 95\% overall accuracy rate).

Our analysis demonstrated that OTSCC can be identified based on the gene expression signature. This finding should provide a foundation for the creation of a specific screen tool for OTSCC. One of the major factors accounting for the poor outcome of OTSCC patients is that a great proportion of oral cancers are diagnosed at advanced stages. Patients diagnosed at an early stage of the disease typically have a better chance for cure and functional outcome. Early detection of tongue cancer lesion will greatly improve patient survival and the quality of life. Current clinical diagnosis and histopathologic examinations are usually based on biopsied material, which requires inva- 


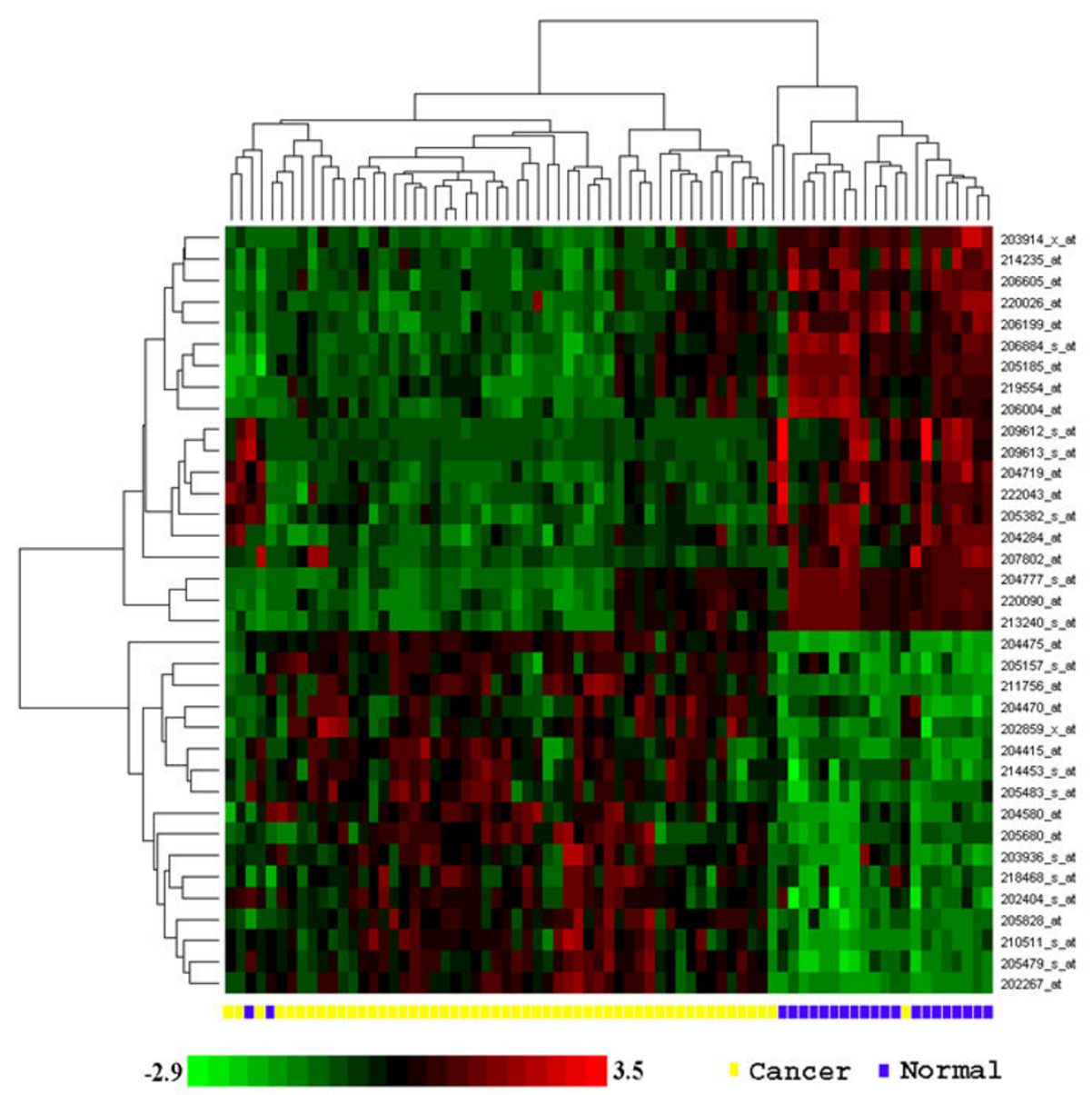

\section{Figure 2}

Classification of OTSCC and matching normal using global gene expression analysis. A signature gene set of 35 genes was created based on RMA analysis of the expression profiles on 53 OTSCC and 22 matching normal samples. Hierarchical clustering was performed based on this signature gene set. To removed the effect of baseline and scale in the color image, the data from every transcript was standardized (remove mean, divide by standard deviation) before plotting.

sive procedures and surgical techniques. The emerging technology of saliva-based diagnosis may provide an alternative strategy for early diagnosis and screening of the subjects at risk [21]. The markers identified here may be suitable for the saliva-based early diagnosis and screening strategy [17,21]. Additional validation studies will be needed to fully explore this possibility.

To gain a better understanding of the underlying molecular biological processes that dictate the observed expressional pattern alterations in OTSCC development, the Gene Ontology analysis was performed. It was carried out using the GOstats package in the Bioconductor [22] and Gene Ontology Consortium database [23], based on the complete list of 365 differentially expressed transcripts (Supplement Table S1 and S2). Among those 365 genes, 306 were mapped to ENTREZ genes. The gene universe in the analysis consists of 13125 transcripts that were mapped to ENTREZ genes. The Gene Ontology analysis suggested a number of altered biological processes in OTSCC. These include enhancement in phosphate transport, collagen catabolism, I-kappaB kinase/NF-kappaB signaling cascade, extracellular matrix organization and biogenesis, chemotaxis, as well as suppression of superoxide release, hydrogen peroxide metabolism, cellular response to hydrogen peroxide, keratinization, keratinocyte differentiation in OTSCCs (Table 2). The complete lists of enhanced and suppressed biological processes, molecular functions and cellular components in OTSCCs were presented in Supplement Table S3 [see additional file 3] and S4 [see additional file 4], respectively.

Among the identified alteration in biological activities in OTSCC, the most significantly enhanced are related to the 
Table 2: Selected biological processes that altered in OTSCCs *

\begin{tabular}{|c|c|c|c|}
\hline GO Name & GO ID & $\%$ Change $* *$ & p-value \\
\hline \multicolumn{4}{|l|}{ Enhanced } \\
\hline Collagen catabolism & GO:0030574 & 38.9 & $2.7 \mathrm{E}-09$ \\
\hline Positive regulation of chemotaxis & GO:005092I & 33.3 & 0.0029 \\
\hline Phosphate transport & GO:00068I7 & 21.7 & $1.5 \mathrm{E}-12$ \\
\hline Extracellular matrix organization and biogenesis & GO:0030198 & 12.9 & 0.00089 \\
\hline Positive regulation of I-kappaB kinase/NF-kappaB cascade & GO:0043123 & 8.8 & 0.00038 \\
\hline \multicolumn{4}{|l|}{ Suppressed } \\
\hline Superoxide release & GO:0042554 & 40.0 & 0.0015 \\
\hline Keratinization & GO:003|424 & 33.3 & I.I E-05 \\
\hline Hydrogen peroxide metabolism & GO:0042743 & 25.0 & 0.0042 \\
\hline Response to hydrogen peroxide & GO:0042542 & 22.2 & 0.0053 \\
\hline Keratinocyte differentiation & GO:0030216 & 21.1 & $8.0 \mathrm{E}-05$ \\
\hline
\end{tabular}

* The complete lists of enhanced and suppressed biological processes (BP), molecular functions (MF) and cellular components (CC) in OTSCCs were presented in Supplement Table S3 and S4, respectively.

** The percent of genes exhibiting expressional changes among all genes that constitutes a specific GO entity.

extracellular matrix remodeling (GO:0030574, GO:0030198), I-kappaB kinase/NF-kappaB cascade (GO:0043123) and chemotaxis (GO:0050921), which are known to be related to tumorgenesis and progression of the cancer. One interesting observation is the enhancement in phosphate transport (GO:0006817) in OTSCC. This may be related directly to the enhanced metabolic activity and energy consumption rate in OTSCCs. It has also been suggested that phosphate can act as a signaling molecule on the extracellular signal-regulated kinase (ERK1/2) [24] and adenylate cyclase/cAMP signaling pathways [25], and ultimately affect cell growth. However, the precise role of enhanced phosphate transport in tumorgenesis is largely unclear. The significantly suppressed biological activities, such as superoxide release (GO:0042554), hydrogen peroxide metabolism (GO:0042743), and response to hydrogen peroxide (GO:0042542) are all appeared to be related to the cellular redox state. The effects of redox state in malignancies are somewhat contradictory. In theory, reducing the oxidative stress may prevent DNA degeneration and therefore prevent the development of cancer. However, doing so may also offer increased growth potential to tumor cells and protect them from excess of reactive oxygen species (ROS), which would otherwise lead to apoptosis or necrosis. At the center of this apparent controversy is superoxide dismutase 2 (SOD2), which has been considered as one of the most important antioxidant enzymes. The role of SODs in carcinogenesis has been widely studied but is still rather ambiguous. While the majority of in vitro studies have reported a protective role of SOD2 against tumor progression in cancer cell lines [26-30], including oral cancer cell lines [31], the in vivo studies indicate more complicated roles. Increased SOD2 levels have been observed from esophageal, gastric, brain astrocytic and colorectal carcinomas, and often associated with metastasis and poor prognosis [32-40]. The status of SOD2 in breast cancer is not clear, with some studies showing an increase [41], while others showing a decrease in SOD2 level [42]. Reduction in SOD2 level has been observed in prostatic carcinomas $[43,44]$. Our microarray results indicated a significant increase in expression of SOD2 gene (probset: $215223 \_s \_a t ;$ fold change $=2.37 ; \mathrm{p}$ value $=$ 0.00014; and probeset: $216841 \_s \_$at; fold change $=2.24$; $\mathrm{p}$ value $=0.000197)$ in OTSCC. These findings are in agreement with the recent observation in oral cancer [45]. Additional studies will be needed to fully understand the role(s) of redox state and SOD2 in OTSCC.

To visualize the changes in gene expression patterns in relationship with the alteration of biological processes and cellular functions in OTSCC, gene expression heat maps for each identified GO entities were generated based on the microarray results of 53 OTSCC and 22 normal samples (Figure 3). Apparent differences in expression patterns can be observed between OTSCC and normal groups for all the altered GO entities. The summarized statistical values on differential expression for each individual gene of GO:0030574 (collagen catabolism) and GO:0050921 (positive regulation of chemotaxis) are presented in Table 3 . The complete expressional analysis for all the altered biological processes identified in Table 2 is presented in Supplement Table S5 [see additional file 5].

Among these differentially expressed genes, some have potential value as diagnosis and prognosis markers, and may be indicative of their respective biological pathways. For example, IL8 is a prototypical chemokine (chemotactic cytokine) and is known for its involvements in the positive regulation of chemotaxis (GO:0050921), which is 


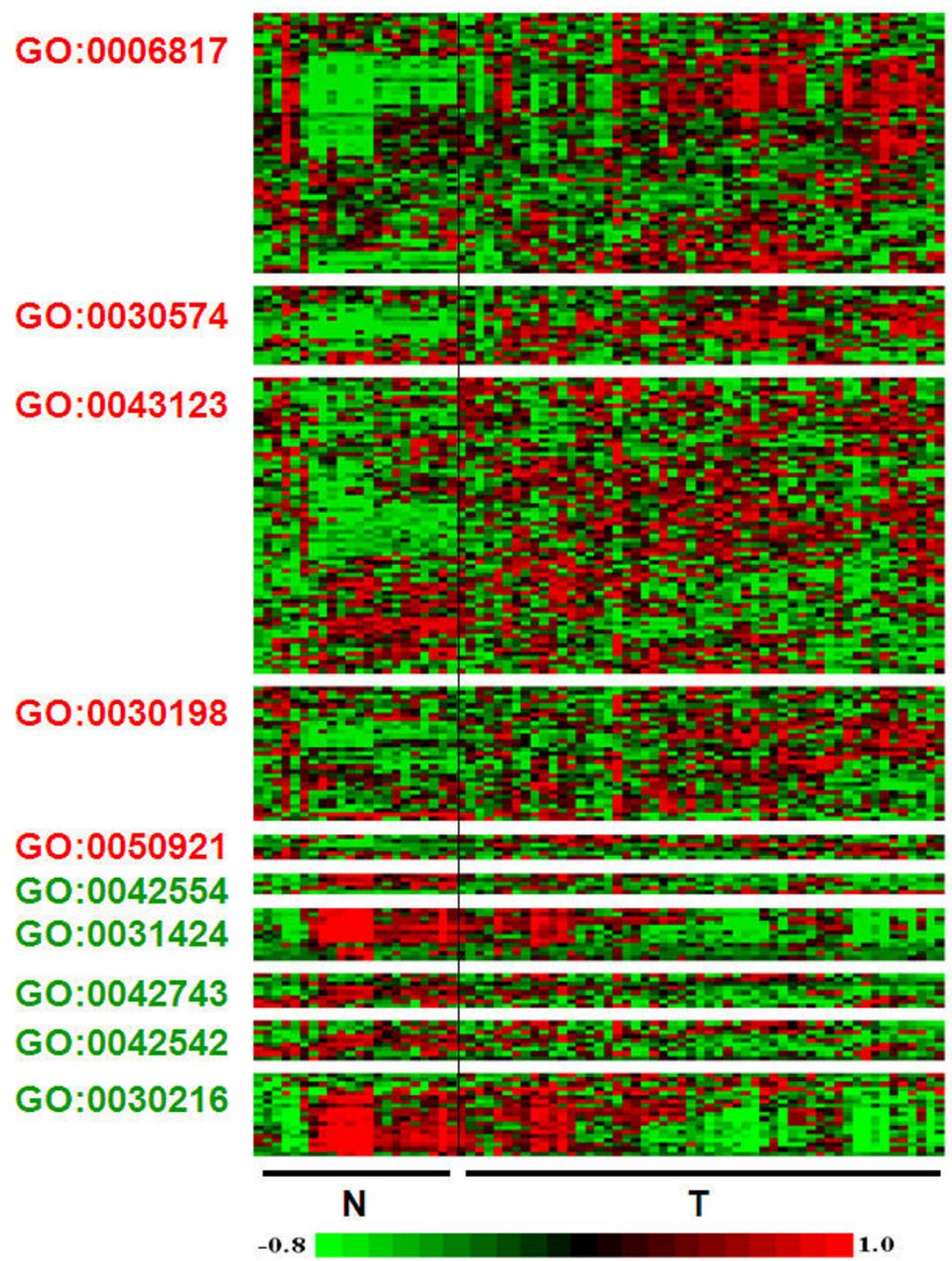

Figure 3

Expression values of the genes constitute of the altered biological processes in OTSCC. The altered biological processes in OTSCC were identified by Gene Ontology analysis (Table 2) as described in the Materials and Methods section. The expression values of the genes consisting of the altered biological processes were extracted from the RMA based expression index, and individual heat maps were generated for the identified altered biological processes in OTSCC. To removed the effect of baseline and scale in the color image, the data from every transcript was standardized (remove mean, divide by standard deviation) before plotting. To increase the contrast, values lower than the $10^{\text {th }}$ percentile were replaced with the $10^{\text {th }}$ percentile, and values higher than the $95^{\text {th }}$ percentile were replaced with the $95^{\text {th }}$ percentile.

enhanced in tongue cancers as indicated by our Gene Ontology analysis. IL8 has also been suggested to be a potential biomarker for the early detection of oral cancer $[16,17]$. The over-expression of the MMP9 gene has been shown to be associated with progression of oral dysplasia to cancer [14]. Our recent study suggested that overexpression of the MMP9 gene is associated with advanced OTSCC and has predictive value for OTSCC lymph node metastasis [15]. The upregulation of MMP9 in OTSCC is also involved in the enhanced collagen catabolism (GO:0030574), as indicated by our Gene Ontology analysis. The qRT-PCR analyze were performed to validate the expressional differences of the IL8 and MMP9 genes between tongue SCCs and normal matching tissues. As shown in Figure 4A and 4B, the differences of both IL8 and MMP9 mRNA levels are statistically significant ( $\mathrm{p}<$ .05) between OTSCC and normal tissues. The expression of MMP9 and IL8 was further confirmed by immunohis- 
Table 3: Expression values of genes that constitute the collagen catabolism (GO:0030574) and positive regulation of chemotaxis (GO:005092I) processes in OTSCC.

\begin{tabular}{|c|c|c|c|c|}
\hline GO term & entrzID & $\begin{array}{l}\text { Gene } \\
\text { Symbol }\end{array}$ & Fold change & FDR level \\
\hline \multicolumn{5}{|c|}{ GO:0030574 } \\
\hline & 4312 & MMPI & 57.6 & 0 \\
\hline & 4313 & MMP2 & 1.44 & 0.109 \\
\hline & 4314 & MMP3 & 8.43 & I.0IE-08 \\
\hline & 4316 & MMP7 & 2.83 & 0.0049 \\
\hline & 4317 & MMP8 & 1.01 & 0.7963 \\
\hline & 4318 & MMP9 & 4.08 & 5.85E-05 \\
\hline & 4319 & MMPIO & 8.45 & 9.95E-06 \\
\hline & 4320 & MMPII & 2.02 & 0.00085 \\
\hline & 4322 & MMPI3 & 3.79 & 0.0007 \\
\hline & 4325 & MMPI 6 & 0.93 & 0.1117 \\
\hline & 4327 & MMPI9 & 1.08 & 0.4404 \\
\hline & 5184 & PEPD & 0.92 & 0.4602 \\
\hline & 5645 & PRSS2 & 0.76 & 0.0187 \\
\hline & 5653 & KLK6 & 0.73 & 0.4218 \\
\hline & 5657 & PRTN3 & 0.96 & 0.2656 \\
\hline & 9508 & ADAMTS3 & 1.05 & 0.5858 \\
\hline & 9509 & ADAMTS2 & 1.19 & 0.2451 \\
\hline & 56547 & MMP26 & 0.94 & 0.2394 \\
\hline \multicolumn{5}{|c|}{ GO:005092I } \\
\hline & 9353 & SLIT2 & 0.88 & 0.1700 \\
\hline & 566 & AZUI & 0.95 & 0.1643 \\
\hline & 3576 & IL8 & 5.87 & I.54E-06 \\
\hline & 6696 & SPPI & 3.23 & 0.0027 \\
\hline & 7422 & VEGF & 1.20 & 0.4614 \\
\hline & 7857 & SCG2 & 1.00 & 0.9901 \\
\hline
\end{tabular}

tochemistry tests performed using monoclonal antibody to IL8 and MMP9 on 10 OTSCC cases (Figure 4C and 4D). Strong positive stained SCC cells were observed in 4 cases for IL8 and 8 cases for MMP9. The observation of positive staining of IL8 in OTSCC cells confirmed that SCC cells are one of the major sources of IL8 production at the site of oral cancer lesion.

\section{Conclusion}

The HNOSCCs are a diverse group of cancers, that develop from many different anatomic sites and are associated with different risk factors [1] and genetic characteristics [2]. This is the first high-resolution genomic profiling study to our knowledge that has focused on identifying unique expression patterns for tongue cancer (OTSCC). OTSCC is one of the most common types of HNOSCC, and is significantly more aggressive than other forms of HNOSCCs, with a propensity for rapid local invasion and spread [6]. Recent epidemiological studies suggested that the incidence of OTSCC is actually increasing in young and middle age groups [3-5]. In this study, we utilized a relatively large sample size (53 OTSCCs and 22 normal matching samples), which enabled us to capture a precise picture of the genome-wide expression pattern for this disease. It is possible that the genomic portrait of HNOSCC originating from different anatomic sites may be different. More studies will be needed to address this important question.

In summary, we identified the unique expression pattern for OTSCC. Several interesting candidate genes associated with OTSCC were identified. The Gene Ontology analysis indicated that several biological processes and cellular functions are consistently altered in OTSCC. Our results demonstrate the feasibility of utilizing biomarkers discovered by global expression profiling analyses for the detection and diagnosis of OTSCC. In addition, we also provided a valuable reference dataset for future identification and validation of biomarkers for detection, diagnosis and prognosis of OTSCC.

\section{Methods \\ Patients}

Microarray data were generated from 26 microdissected OTSCC tissues and 12 matching normal tissue samples. Three additional microarray datasets from 27 OTSCC cases and 10 matching normal control tissues that published previously were either downloaded from GEO database (GSE2280, [46] and GSE3524, [47]) or requested from the authors [7]. Clinical characterizations of these patients are outlined in Table 4 . The tumor stages were determined according to the American Joint Committee on Cancer (AJCC) designated classification. This study is approved by Institutional Review Boards at University of California at Los Angeles and at University of Illinois at Chicago.

\section{Tumor procurement, RNA extraction and microarray hybridization}

The OTSCC tissues and their matching normal samples were obtained for this study. These tissues were snap frozen. Cancer tissues containing more than $80 \%$ tumor cells based on haematoxylin and eosin (H\&E) staining and pathological examination were identified and selectively microdissected by a trained pathologist. The total RNA was isolated using RNeasy Mini kit (Qiagen), and quantified by the RiboGreen RNA Quantitation Reagent (Molecular Probes). A total of 150-200 ng of purified total RNA was amplified by a modified T7 RNA amplification protocol as described previously $[15,17]$. The Enzo BioArray High Yield RNA Transcript Labeling System (Enzo) was used for labeling the sample prior to hybridization. The biotinylated cRNA (IVT product) was purified using the RNeasy kit (Qiagen). The quantity and purity of the biotinylated cRNA was determined by spectrophotometry and an aliquot of the sample was checked by gel electrophoresis. The samples were hybridized to the Affymetrix Human Genome U133 Plus 2.0 GeneChip arrays accord- 
A
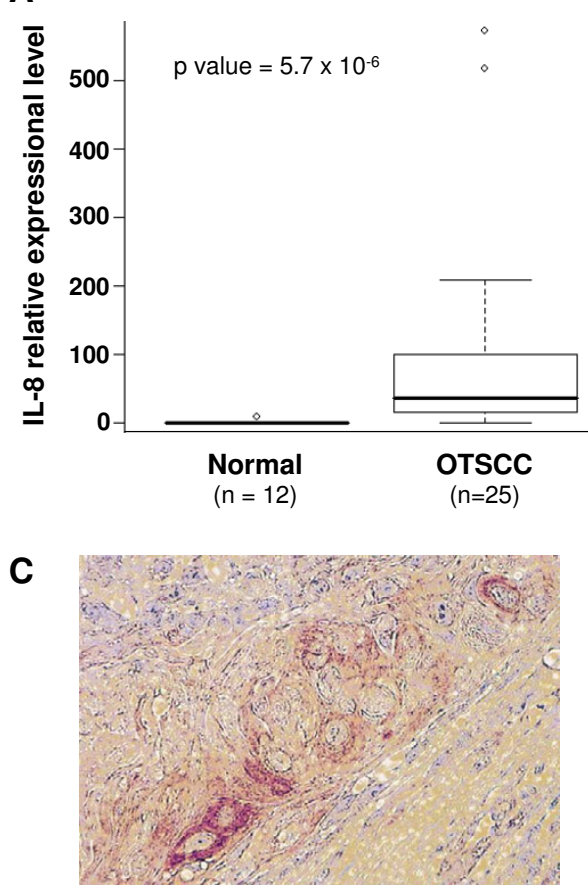

B

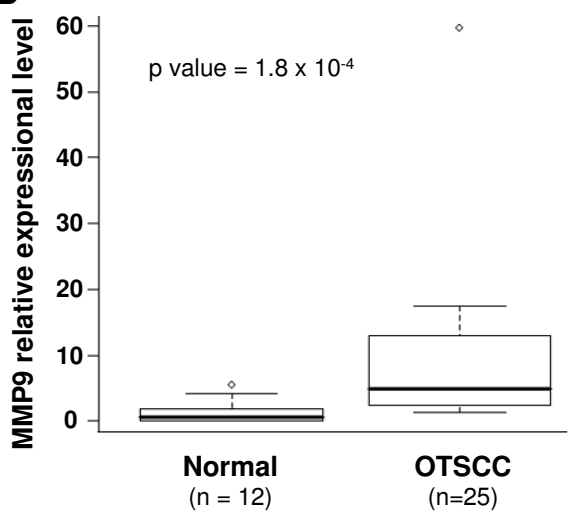

D

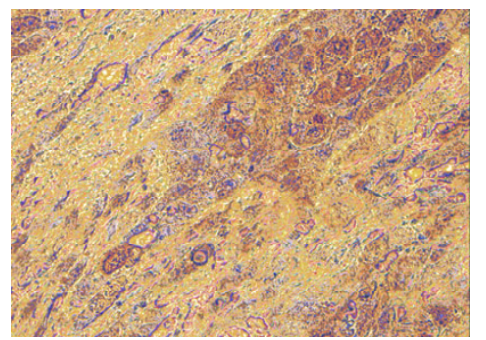

Figure 4

Elevated expressions of IL8 and MMP9 genes in OTSCC. The qRT-PCR tests were performed with primer sets specific for IL8 gene (A) and MMP9 gene (B) on 25 OTSCC cases and 12 normal matching samples. The $p$ values (Wilcoxon test) were presented. Immunohistochemistry tests were performed using monoclonal antibody to IL8 and MMP9 and detected using peroxidase-antiperoxidase and diaminebenzadine (DAB) on 10 OTSCC cases. Positive stained SCC cells were observed in 4 cases for IL8 and 8 cases for MMP9. Representative images for IL8 (C) and MMP9 (D) were presented.

ing to the Affymetrix protocols. The arrays were scanned with a GeneChip Scanner 3000. The scanned array images were processed with GeneChip Operating software (GCOS), and the CEL files were extracted for further analysis.

Table 4: Clinical Characterization of the OTSCC Patients*

\begin{tabular}{llll}
\hline & & OTSCC ( $\mathrm{n}=53)$ & $\begin{array}{l}\text { Normal } \\
(\mathrm{n}=22)\end{array}$ \\
\hline Age & Average & 57 & 56 \\
Gender & (Range) & $32-82$ & $37-78$ \\
& Male (\%) & 73.6 & 59.1 \\
Anatomic Site & Female (\%) & 26.4 & 40.9 \\
Pathological T Stage & Tongue (\%) & 100 & 100 \\
& Stage 4 (\%) & 56.6 & \\
& Stage 3 (\%) & 7.5 & \\
Pathological N & Stage 2 (\%) & 22.6 & \\
Stage & Stage I (\%) & 13.2 & \\
& Stage 2 (\%) & 43.4 & \\
& & & \\
& Stage I (\%) & 7.5 & \\
& Stage 0 (\%) & 49.1 &
\end{tabular}

\footnotetext{
* The $M$ stage data is not available.
}

\section{Array data analysis and gene ontology analysis}

The CEL files from all datasets (newly generated array data from 26 OTSCCs and 12 matching normals, and additional 27 OTSCCs and 10 normals from published studies $[7,46,47])$ were imported into the statistical software $\mathrm{R}$ 2.4.1 [48] using Bioconductor [49]. The meta-analysis was performed as described [50]. In brief, the Robust MultiArray Average (RMA) expression measures [51] were computed after background correction and quantile normalization for each microarray dataset. Then, expression values of the overlapping probesets between U133A and U133 Plus 2.0 arrays were extracted. Probeset-level quantile normalization was performed across all samples to make the effect sizes similar among the four datasets. To visualize the overall expression patterns, we performed Principal Component Analysis (PCA) after removing the normal group mean vector separately from each of the four datasets. Finally, for every probeset, a mixed effects model was applied to identify differential expression. For gene $i$ in sample $k$ of experiment $j$, 


$$
\begin{aligned}
y_{i j k}=m_{i}+a_{i j}+b_{i} x_{i j k}+e_{i j k}, a_{i j} & \sim N\left(0, d_{i}\right), e_{i j k} \sim N\left(0, s_{i}\right) \\
x_{i j k} & = \begin{cases}1, & \text { cancer } \\
0, & \text { normal }\end{cases}
\end{aligned}
$$

In the model, the random effect $\alpha_{i j}$ is the laboratory effect, and $\beta_{i}$ is the first-order cancer effect, which is our major focus in the identification of cancer-associated genes. After obtaining the estimates and the p-values of the $\beta_{i}$ 's of each probeset, we corrected the p-values for false discovery rate (FDR) [52]. We selected genes at the FDR level of 0.01 , and with cancer effect size $>1$ ( $>2$ fold change between cancer and normal samples). Functional analysis of the differentially expressed genes was carried out using the GOstats package in Bioconductor [22] based on the Gene Ontology Consortium database [23].

\section{Quantitative RT-PCR(qRT-PCR)}

The mRNA levels of interleukin-8 (IL8) and matrix metalloproteinases 9 (MMP9) in OTSCCs and normal tissues were further validated using qRT-PCR as previously described $[15,17]$. The RNA was converted to first strand cDNA using MuLV reverse transcriptase (Applied Biosystems) and the quantitative PCR was performed using iQ SYBR Green Supermix (Bio-Rad) in a BIO-RAD iCycler iQ real-time PCR detection system. The primer sets specific for IL8 (Forward: 5'-GAGGGTTGTGGAGAAGTTTTTG-3', Reverse: 5'-CTGGCATCTTCACTGATTCTTG-3') and for MMP9 (Forward: 5'-GCACGACGTCTTCCAGTACC-3', Reverse: 5'-TCAACTCACTCCGGGAACTC-3') were used. All reactions were performed in triplicate. The melting curve analyses were performed to ensure the specificity of the qRT-PCR reactions. The data analysis was performed using the 2-deltadelta $\mathrm{Ct}$ method described previously [53], where beta-actin was used as reference gene. The qRT-PCR based gene expression values between two groups were compared by the nonparametric Wilcoxon test.

\section{Immunohistochemistry}

The expression of IL8 and MMP9 in OTSCCs were further examined using immunohistochemistry tests as previously described [54]. In brief, the OTSCC tissues were processed, embedded, and sectioned at $5 \mu \mathrm{m}$. Tissue sections were stained using monoclonal antibody to IL8 (MAB208) (R \& D Systems) and MMP9 (ab51203) (Abcam, Inc) and detected using peroxidase-antiperoxidase and diaminebenzadine (DAB) with a Discovery XT automated instrument (Ventana Medical Systems, Inc).

\section{Authors' contributions}

$\mathrm{BZ}, \mathrm{LM}, \mathrm{DW}$, and $\mathrm{XZ}$ conceived the idea for the project and drafted the manuscript. HY, TY, ST, JS, JW and XZ performed the laboratory analyses and conducted statistical analyses. JS and JW provided discussions on clinical rele- vance. $\mathrm{BZ}$, JS, JW, LM, DW and XZ revised the manuscript. All authors read and approved the final manuscript.

\section{Additional material}

\author{
Additional file 1 \\ Supplement Table S1: Up-regulated transcripts in OTSCC. The table \\ showing the complete list of the up-regulated transcripts in OTSCC ( $p$ \\ value $<0.01$; fold increase $>2.0$ ). \\ Click here for file \\ [http://www.biomedcentral.com/content/supplementary/1471- \\ 2164-9-69-S1.doc]

\section{Additional file 2} \\ Supplement Table S2: Down-regulated transcripts in OTSCC. The \\ table showing the complete list of the down-regulated transcripts in \\ OTSCC ( $p$ value < 0.01; fold increase < 0.5). \\ Click here for file \\ [http://www.biomedcentral.com/content/supplementary/1471- \\ 2164-9-69-S2.doc]
}

\section{Additional file 3}

Supplement Table S3: Enhanced Biological Processes (BP), Molecular Functions (MF) and Cellular Components (CC) in OTSCC. The table showing the complete list of the enhanced biological processes (BP), molecular functions (MF) and cellular components (CC) in OTSCC ( $p$ value < 0.01)

Click here for file

[http://www.biomedcentral.com/content/supplementary/14712164-9-69-S3.doc]

\section{Additional file 4}

Supplement Table S4: Suppressed Biological Processes (BP), Molecular Functions (MF) and Cellular Components (CC) in OTSCC. The table showing the complete list of the suppressed biological processes (BP), molecular functions (MF) and cellular components (CC) in OTSCC ( $p$ value <0.01).

Click here for file

[http://www.biomedcentral.com/content/supplementary/1471-

2164-9-69-S4.doc]

\section{Additional file 5}

Supplement Table S5: Expression values of genes that constitute the altered biological processes (listed in Table 2) in OTSCC. The table showing the statistics on expression values of genes that constitute the altered biological processes in OTSCC.

Click here for file

[http://www.biomedcentral.com/content/supplementary/14712164-9-69-S5.doc]

\section{Acknowledgements}

This work was supported in part by NIH PHS grants K22 DE0 I4847, RO3 DEOI6569, and RO3 CAII 4688 (to X. Zhou), ROI DEOI5970 (to D.

Wong), P0I CA 10645 I Project 3 (to L. Mao), and a Foundation de France grant (to S. Temam). We thank Drs. O'Donnell and Muschel at Children's Hospital of Philadelphia and Dr Dermody at University of Medicine and Dentistry of New Jersey for sharing their microarray datasets with us. We thank Mr. Hui Zhou and Ms. Nisa Pungpravat for their excellent technical assistance, and Ms. Katherine Long for editorial assistance. 


\section{References}

I. Dobrossy L: Epidemiology of head and neck cancer: magnitude of the problem. Cancer Metastasis Rev 2005, 24(I):9-I7.

2. Timar J, Csuka O, Remenar E, Repassy G, Kasler M: Progression of head and neck squamous cell cancer. Cancer Metastasis Rev 2005, 24(I): 107-127.

3. Mackenzie J, Ah-See K, Thakker N, Sloan P, Maran AG, Birch J, Macfarlane G]: Increasing incidence of oral cancer amongst young persons: what is the aetiology? Oral Oncol 2000, 36(4):387-389.

4. Annertz K, Anderson H, Biorklund A, Moller T, Kantola S, Mork J, Olsen $\mathrm{JH}$, Wennerberg $\mathrm{J}$ : Incidence and survival of squamous cell carcinoma of the tongue in Scandinavia, with special reference to young adults. Int J Cancer 2002, I 0 I(I):95-99.

5. Schantz SP, Yu GP: Head and neck cancer incidence trends in young Americans, 1973-1997, with a special analysis for tongue cancer. Arch Otolaryngol Head Neck Surg 2002, I 28(3):268-274

6. Franceschi D, Gupta R, Spiro RH, Shah JP: Improved survival in the treatment of squamous carcinoma of the oral tongue. Am J Surg 1993, I66(4):360-365.

7. Ziober AF, Patel KR, Alawi F, Gimotty P, Weber RS, Feldman MM, Chalian AA, Weinstein GS, Hunt J, Ziober BL: Identification of a gene signature for rapid screening of oral squamous cell carcinoma. Clin Cancer Res 2006, I 2(20 Pt I):5960-597I.

8. Mendez E, Cheng C, Farwell DG, Ricks S, Agoff SN, Futran ND, Weymuller EA Jr., Maronian NC, Zhao LP, Chen C: Transcriptional expression profiles of oral squamous cell carcinomas. Cancer 2002, 95(7): | 482-1494

9. Arora S, Matta A, Shukla NK, Deo SV, Ralhan R: Identification of differentially expressed genes in oral squamous cell carcinoma. Mol Carcinog 2005, 42(2):97-108.

10. Kuo WP, Hasina R, Ohno-Machado L, Lingen MW: Classification and identification of genes associated with oral cancer based on gene expression profiles. A preliminary study. $N$ Y State Dent J 2003, 69(2):23-26.

II. Moilanen M, Sorsa T, Stenman M, Nyberg P, Lindy O, Vesterinen J, Paju A, Konttinen YT, Stenman UH, Salo T: Tumor-associated trypsinogen-2 (trypsinogen-2) activates procollagenases (MMP-I, -8, -I3) and stromelysin-I (MMP-3) and degrades type I collagen. Biochemistry 2003, 42( I 8):54|4-5420.

12. Rosenthal EL, Matrisian LM: Matrix metalloproteases in head and neck cancer. Head Neck 2006, 28(7):639-648.

13. Fingleton B: Matrix metalloproteinases: roles in cancer and metastasis. Front Biosci 2006, I I:479-49 I.

14. Jordan RC, Macabeo-Ong M, Shiboski CH, Dekker N, Ginzinger DG, Wong DT, Schmidt BL: Overexpression of matrix metalloproteinase- $I$ and -9 mRNA is associated with progression of oral dysplasia to cancer. Clin Cancer Res 2004, I O( I 9):6460-6465.

15. Zhou X, Temam S, Oh M, Pungpravat N, Huang BL, Mao L, Wong DT: Global expression-based classification of lymph node metastasis and extracapsular spread of oral tongue squamous cell carcinoma. Neoplasia 2006, 8( I I):925-932

16. St John MA, Li Y, Zhou X, Denny P, Ho CM, Montemagno C, Shi W, Qi F, Wu B, Sinha U, Jordan R, Wolinsky L, Park NH, Liu H, Abemayor E, Wong DT: Interleukin 6 and interleukin 8 as potential biomarkers for oral cavity and oropharyngeal squamous cell carcinoma. Arch Otolaryngol Head Neck Surg 2004, I 30(8):929-935.

17. Li Y, St John MA, Zhou X, Kim Y, Sinha U, Jordan RC, Eisele D, Abemayor E, Elashoff D, Park NH, Wong DT: Salivary transcriptome diagnostics for oral cancer detection. Clin Cancer Res 2004 I 0(24):8442-8450.

18. Minn AJ, Gupta GP, Siegel PM, Bos PD, Shu W, Giri DD, Viale A, Olshen $A B$, Gerald WL, Massague J: Genes that mediate breast cancer metastasis to lung. Nature 2005, 436(7050):5 I 8-524.

19. Yang G, Rosen DG, Zhang Z, Bast RC Jr., Mills GB, Colacino JA, Mer cado-Uribe I, Liu J: The chemokine growth-regulated oncogene I (Gro-I) links RAS signaling to the senescence of stromal fibroblasts and ovarian tumorigenesis. Proc Natl Acad Sci U S A 2006, I03(44): I6472-16477.

20. Shintani S, Ishikawa T, Nonaka T, Li C, Nakashiro K, Wong DT, Hamakawa $\mathrm{H}$ : Growth-regulated oncogene-I expression is associated with angiogenesis and lymph node metastasis in human oral cancer. Oncology 2004, 66(4):316-322.

21. Wong DT: Towards a simple, saliva-based test for the detection of oral cancer 'oral fluid (saliva), which is the mirror of the body, is a perfect medium to be explored for health and disease surveillance'. Expert Rev Mol Diagn 2006, 6(3):267-272.

22. Falcon S, Gentleman R: Using GOstats to test gene lists for GO term association. Bioinformatics 2007, 23(2):257-258.

23. Ashburner M, Ball CA, Blake JA, Botstein D, Butler $H$, Cherry JM, Davis AP, Dolinski K, Dwight SS, Eppig JT, Harris MA, Hill DP, IsselTarver L, Kasarskis A, Lewis S, Matese JC, Richardson JE, Ringwald M, Rubin GM, Sherlock G: Gene ontology: tool for the unification of biology. The Gene Ontology Consortium. Nat Genet 2000, 25(I):25-29.

24. Beck GR Jr., Knecht N: Osteopontin regulation by inorganic phosphate is ERKI/2-, protein kinase C-, and proteasomedependent. J Biol Chem 2003, 278(43):4I92।-4I929.

25. Naviglio S, Spina A, Chiosi E, Fusco A, Illiano F, Pagano M, Romano M, Senatore G, Sorrentino A, Sorvillo L, Illiano G: Inorganic phosphate inhibits growth of human osteosarcoma U2OS cells via adenylate cyclase/cAMP pathway. J Cell Biochem 2006, 98(6): I $584-1596$.

26. Yan T, Oberley LW, Zhong W, St Clair DK: Manganese-containing superoxide dismutase overexpression causes phenotypic reversion in SV40-transformed human lung fibroblasts. Cancer Res 1996, 56( I 2):2864-287I

27. Zhong W, Oberley LW, Oberley TD, Yan T, Domann FE, St Clair DK: Inhibition of cell growth and sensitization to oxidative damage by overexpression of manganese superoxide dismutase in rat glioma cells. Cell Growth Differ 1996, 7(9): I I75- I I86.

28. Church SL, Grant JW, Ridnour LA, Oberley LW, Swanson PE, Meltzer PS, Trent JM: Increased manganese superoxide dismutase expression suppresses the malignant phenotype of human melanoma cells. Proc Natl Acad Sci U S A 1993, 90(7):3 I I 3-3 I I 7.

29. Cullen J], Weydert C, Hinkhouse MM, Ritchie J, Domann FE, Spitz D, Oberley LW: The role of manganese superoxide dismutase in the growth of pancreatic adenocarcinoma. Cancer Res 2003, 63(6): I297-1303

30. Ough M, Lewis A, Zhang Y, Hinkhouse MM, Ritchie JM, Oberley LW, Cullen J): Inhibition of cell growth by overexpression of manganese superoxide dismutase (MnSOD) in human pancreatic carcinoma. Free Radic Res 2004, 38(I I): I223-I 233.

31. Liu R, Oberley TD, Oberley LW: Transfection and expression of MnSOD cDNA decreases tumor malignancy of human oral squamous carcinoma SCC-25 cells. Hum Gene Ther 1997, 8(5):585-595.

32. Izutani R, Asano S, Imano M, Kuroda D, Kato M, Ohyanagi H: Expression of manganese superoxide dismutase in esophageal and gastric cancers. / Gastroenterol 1998, 33(6):8|6-822.

33. Malafa M, Margenthaler J, Webb B, Neitzel L, Christophersen M: MnSOD expression is increased in metastatic gastric cancer. J Surg Res 2000, 88(2): I30-134.

34. Kim JJ, Chae SW, Hur GC, Cho SJ, Kim MK, Choi J, Nam SY, Kim WH, Yang HK, Lee BL: Manganese superoxide dismutase expression correlates with a poor prognosis in gastric cancer. Pathobiology 2002, 70(6):353-360.

35. Janssen AM, Bosman CB, Sier CF, Griffioen G, Kubben FJ, Lamers CB, van Krieken JH, van de Velde CJ, Verspaget HW: Superoxide dismutases in relation to the overall survival of colorectal cancer patients. $\mathrm{Br} /$ Cancer 1998, 78(8): $1051-1057$.

36. Toh Y, Kuninaka S, Oshiro T, Ikeda Y, Nakashima H, Baba H, Kohnoe $\mathrm{S}$, Okamura T, Mori M, Sugimachi K: Overexpression of manganese superoxide dismutase mRNA may correlate with aggressiveness in gastric and colorectal adenocarcinomas. Int J Oncol 2000, I 7(1): 107-I I2.

37. Haapasalo H, Kylaniemi M, Paunul N, Kinnula VL, Soini Y: Expression of antioxidant enzymes in astrocytic brain tumors. Brain Pathol 2003, I3(2): I55-164.

38. Korenaga D, Yasuda M, Honda M, Nozoe T, Inutsuka S: MnSOD expression within tumor cells is closely related to mode of invasion in human gastric cancer. Oncol Rep 2003, I O(I):27-30.

39. Nozoe T, Honda M, Inutsuka S, Yasuda M, Korenaga D: Significance of immunohistochemical expression of manganese superoxide dismutase as a marker of malignant potential in colorectal carcinoma. Oncol Rep 2003, I O(I):39-43.

40. Qi Y, Chiu JF, Wang L, Kwong DL, He QY: Comparative proteomic analysis of esophageal squamous cell carcinoma. Proteomics 2005, 5( I I):2960-297I.

41. Bianchi MS, Bianchi NO, Bolzan AD: Superoxide dismutase activity and superoxide dismutase-I gene methylation in normal 
and tumoral human breast tissues. Cancer Genet Cytogenet 1992, 59(1):26-29.

42. Soini Y, Vakkala M, Kahlos K, Paakko P, Kinnula V: MnSOD expression is less frequent in tumour cells of invasive breast carcinomas than in in situ carcinomas or non-neoplastic breast epithelial cells. J Pathol 200I, 195(2): I56-162.

43. Baker AM, Oberley LW, Cohen MB: Expression of antioxidant enzymes in human prostatic adenocarcinoma. Prostate 1997, 32(4):229-233.

44. Bostwick DG, Alexander EE, Singh R, Shan A, Qian J, Santella RM, Oberley LW, Yan T, Zhong W, Jiang X, Oberley TD: Antioxidant enzyme expression and reactive oxygen species damage in prostatic intraepithelial neoplasia and cancer. Cancer 2000, 89(I): $123-134$.

45. Lo WY, Tsai MH, Tsai Y, Hua CH, Tsai FJ, Huang SY, Tsai CH, Lai CC: Identification of over-expressed proteins in oral squamous cell carcinoma (OSCC) patients by clinical proteomic analysis. Clin Chim Acta 2007, 376( I-2): I0I-I07.

46. O'Donnell RK, Kupferman M, Wei SJ, Singhal S, Weber R, O'Malley B, Cheng Y, Putt M, Feldman M, Ziober B, Muschel RJ: Gene expression signature predicts lymphatic metastasis in squamous cell carcinoma of the oral cavity. Oncogene 2005, 24(7):|244-|25|.

47. Toruner GA, Ulger C, Alkan M, Galante AT, Rinaggio J, Wilk R, Tian B, Soteropoulos P, Hameed MR, Schwalb MN, Dermody J]: Association between gene expression profile and tumor invasion in oral squamous cell carcinoma. Cancer Genet Cytogenet 2004, I 54(I):27-35.

48. R_Development_Core_Team: R: A language and environment for statistical computing. In R Foundation for Statistical Computing Vienna, Austria ; 2006.

49. Gentleman RC, Carey VJ, Bates DM, Bolstad B, Dettling M, Dudoit S, Ellis B, Gautier L, Ge Y, Gentry J, Hornik K, Hothorn T, Huber W, lacus S, Irizarry R, Leisch F, Li C, Maechler M, Rossini AJ, Sawitzki G, Smith C, Smyth G, Tierney L, Yang JY, Zhang J: Bioconductor: open software development for computational biology and bioinformatics. Genome Biol 2004, 5( I 0):R80.

50. Yu T, Ye H, Chen Z, Ziober BL, Zhou X: Dimension reduction and mixed-effects model for microarray meta-analysis of cancer. Front Biosci 2008, 13:27|4-2720.

5I. Irizarry RA, Bolstad BM, Collin F, Cope LM, Hobbs B, Speed TP: Summaries of Affymetrix GeneChip probe level data. Nucleic Acids Res 2003, 3 I(4):el5.

52. Benjamini $Y$, Hochberg $Y$ : Controlling the false discovery rate: a practical and powerful approach to multiple testing. Journal of the Royal Statistical Society Series B 1995, 57:289-300.

53. Livak KJ, Schmittgen TD: Analysis of relative gene expression data using real-time quantitative PCR and the 2(-Delta Delta C(T)) Method. Methods 200I, 25(4):402-408.

54. Peng $\mathrm{H}$, Shintani S, Kim Y, Wong DT: Loss of p/2CDK2-AP expression in human oral squamous cell carcinoma with disrupted transforming growth factor-beta-Smad signaling pathway. Neoplasia 2006, 8(12):1028-1036.
Publish with Biomed Central and every scientist can read your work free of charge

"BioMed Central will be the most significant development for disseminating the results of biomedical research in our lifetime. "

Sir Paul Nurse, Cancer Research UK

Your research papers will be:

- available free of charge to the entire biomedical community

- peer reviewed and published immediately upon acceptance

- cited in PubMed and archived on PubMed Central

- yours - you keep the copyright

Submit your manuscript here:

http://www.biomedcentral.com/info/publishing_adv.asp
BioMedcentral 